\title{
Green Synthesized Silver Nanoparticles as Potent Antifungal Agent against Aspergillus terreus Thom
}

\author{
Faiza Anum, ${ }^{1,2}$ Khajista Jabeen ${ }^{D},{ }^{1}$ Sumera Javad, ${ }^{1}$ Sumera Iqbal, ${ }^{1}$ Arifa Tahir, ${ }^{3}$ \\ Zeeshan Javed, ${ }^{3}$ Natália Cruz-Martins ${ }^{\mathbb{D}},{ }^{4,5,6}$ Seyed Abdulmajid Ayatollahi ${ }^{\mathbb{D}},{ }^{7,8,9}$ \\ Javad Sharifi-Rad $\mathbb{D},{ }^{7}$ Mohammed M. Alshehri $\mathbb{D}^{10}{ }^{10}$ and William C. Cho $\mathbb{D}^{11}$ \\ ${ }^{1}$ Department of Botany, Lahore College for Women University, Lahore, Pakistan \\ ${ }^{2}$ Office of Research Innovation and Commercialization, Lahore Garrison University, Lahore, Pakistan \\ ${ }^{3}$ Department of Environmental Sciences, Lahore College for Women University, Lahore, Pakistan \\ ${ }^{4}$ Faculty of Medicine, University of Porto, Alameda Prof. Hernâni Monteiro, 4200-319 Porto, Portugal \\ ${ }^{5}$ Institute for Research and Innovation in Health (i3S), University of Porto, 4200-135 Porto, Portugal \\ ${ }^{6}$ Institute of Research and Advanced Training in Health Sciences and Technologies (CESPU), Rua Central de Gandra, 1317, \\ 4585-116 Gandra PRD, Portugal \\ ${ }^{7}$ Phytochemistry Research Center, Shahid Beheshti University of Medical Sciences, Tehran, Iran \\ ${ }^{8}$ Department of Pharmacognosy and Biotechnology, School of Pharmacy, Shahid Beheshti University of Medical Sciences, \\ Tehran, Iran \\ ${ }^{9}$ H.E.J. Research Institute of Chemistry, International Center for Chemical and Biological Sciences, University of Karachi, \\ Karachi, Pakistan \\ ${ }^{10}$ Pharmaceutical Care Department, Ministry of National Guard-Health Affairs, Riyadh, Saudi Arabia \\ ${ }^{11}$ Department of Clinical Oncology, Queen Elizabeth Hospital, Kowloon, Hong Kong
}

Correspondence should be addressed to Khajista Jabeen; khajista_1@hotmail.com, Natália Cruz-Martins; ncmartins@med.up.pt, Javad Sharifi-Rad; javad.sharifirad@gmail.com, and William C. Cho; chocs@ha.org.hk

Received 6 May 2021; Revised 9 July 2021; Accepted 7 August 2021; Published 27 August 2021

Academic Editor: Donglu Shi

Copyright (C) 2021 Faiza Anum et al. This is an open access article distributed under the Creative Commons Attribution License, which permits unrestricted use, distribution, and reproduction in any medium, provided the original work is properly cited.

Medicinal plants are composed of a rich pool of biomolecules and have been increasingly recognized for their antimicrobial properties; however, increasing concerns have been put on the bioavailability features. Thus, this study is aimed at exploring the synthesis and characterization of silver nanoparticles synthesized by Chenopodium album L. leaf extract and assessing the antifungal activity against Aspergillus terreus Thom. Plant extract was prepared in methanol to synthetize silver nanoparticles, which were then characterized by Scanning Electron Microscopy (SEM), UV-Visible spectroscopy, and particle size analysis. UV-Visible analysis indicated maximum absorption at $378 \mathrm{~nm}$, and an average particle size was observed as $25.6 \mathrm{~nm}$. Oval to hexagonal shape was observed by SEM. Antifungal activity of silver nanoparticles (1, 1.5, 2, 2.5, 3, and 3.5\%) was addressed against $A$. terreus biomass. At 3.5\%, silver nanoparticles revealed to be highly effective, leading to $92 \%$ retardation in fungus growth. In next phase, various organic fractions, viz., chloroform, $n$-butanol, $n$-hexane, and ethyl acetate, were obtained from plant methanol extract, and the corresponding silver nanoparticles were prepared. These fractions were also assessed for antifungal activity, and $n$-hexane fraction led to $64 \%$ inhibition in A. terreus biomass. Following gas chromatography-mass spectrometry (GC-MS), 18 compounds were identified, namely, 1,3-cyclopentadiene-5-(1 methylethylidene and o-xylene), ethyl benzene, octadecane, nonane, decane, 2-methylheptane, $n$-hexadecane, 2-methylheptane, and eicosane, along with carbonyl compounds (4,4-dimethyl-3-hexanone) and phenols, like stearic acid, propionic acid hydrazide, and 2,4-di-Tbutylphenol. These findings proved that C. album silver nanoparticles are highly effective against A. terreus. 


\section{Introduction}

Aspergillus terreus Thom belongs to the Ascomycetes class and causes postharvest diseases in a number of economically important crops, including wheat, rice, maize, soybean, and potato. With a growth pattern presenting as branched hyphae, white colonies, globose-shaped conidia (diameter $1.5-2.3 \mu \mathrm{m}$ ), and broom-shaped conidiophore [1], this fungus also produces various harmful metabolites, i.e., territrem A, B, and C, which increase its pathogenicity [2]. For example, A. terreus causes foliar blight in potato (Solanum tuberosum L.), identified by the presence of a dark colored leaf pinnacle that contains up to $35-65 \%$ of the entire leaf surface [3].

Physical control of $A$. terreus can be done by crop rotation, being those cultivars less susceptible to disease, and thus can be planted to minimize disease spread up to some extent [4]. Also, a postharvest disease can be chemically controlled using a fungicide spray upon growing season onset, leading to a disease control up to $90 \%$ [5]. Nevertheless, despite a proper timing and fungicide amount can prevent the crop, chemical fungicides are not environment friendly and not cost effective as well [6].

Increasing evidences have shown that natural products can be useful to reach a proper biological control of plant pests, attributed to the presence of several secondary metabolites, which control the disease up to an extent. Plant-derived phytochemicals, like saponins, alkaloids, terpenoids, flavonoids, tannins, and cardiac glycosides, have shown excellent antifungal properties against pathogenic fungi [7-11].

Chenopodium album L. is a member of Chenopodiaceae family, Chenopodium genus with a rich content of chemical constituents, including carbohydrates, sodium, calcium, potassium, zinc, and $\beta$-carotene and secondary metabolites, like saponins, tannins, alkaloids, terpenoids, and cardiac glycosides [9, 12]. C. album leave extract possesses antifungal potential of against Ascochyta rabiei. Various concentrations (1-7\%) of methanolic extracts were prepared and checked against $A$. rabiei. 7\% concentration exhibited strong antifungal activity up to $68 \%$ against test fungus [8]. It was reported that antimicrobial property of C. album was due to presence of saponins, flavonoids, alkaloids, phenolics, ascorbic acids, calcium, phosphate, minerals, salts, and protein [12].

Nanotechnology is an interdisciplinary field focus on nano-sized elements with a range in size from 1 to $100 \mathrm{~nm}$ [13]. However, the nanoparticle synthesis using chemicals following reduction method is not safe and is linked to many biological hazards, i.e., poisoning and threatening ecofriendly environment. Due to these problems, biological methods are preferred for nanoparticle synthesis. Thus, the nanoparticle formation using green synthesis is chosen nowadays over chemical method as it is an eco-friendly approach, where phytochemicals present in plant perform reduction of salt solution and stabilization of nanoparticles [13]. In this sense, the present study is aimed at synthetizing and characterizing the silver nanoparticles synthesized by Chenopodium album L. leaf extract and at assessing their antifungal activity against Aspergillus terreus Thom.

\section{Materials and Methods}

2.1. Collection of Experimental Material. Chenopodium album was taken from Phool Nagar, Punjab, Pakistan. The test plant was surface sterilized using sodium hypochloride (1\%) solution and then washed with distilled water. Dried plants were dried and stored at room temperature. Aspergillus terreus cultures were from the Fungal Culture Bank of Pakistan, University of the Punjab, Lahore, and preserved on malt extract (ME) medium.

2.2. Synthesis and Characterization of Silver Nanoparticles. A $4 \mathrm{mM}$ silver nitrate solution was prepared by dissolving $0.68 \mathrm{~g}$ of $\mathrm{AgNO}_{3}$ in $100 \mathrm{~mL}$ of distilled water. In $30 \mathrm{~mL}$ of the test plant extract, $30 \mathrm{~mL}$ of $\mathrm{AgNO}_{3}$ solution was added in $250 \mathrm{~mL}$ beaker, with beaker being then covered with an aluminum foil. The solution was kept in dark for $2 \mathrm{~h}$ for incubation, and changes in the solution color were observed after interval of 2,4 , and $24 \mathrm{~h}$. After $24 \mathrm{~h}$, the solution was centrifuged at $5000 \mathrm{rpm}$ for $10 \mathrm{~min}$, the supernatant was removed, and pellet was stored at $4^{\circ} \mathrm{C}$.

Silver ion reduction in colloidal solution was checked on UV-Visible spectroscopy to confirm the synthesis of silver nanoparticles. For this purpose, small sample amounts were taken and analyzed between wavelengths of 300 and $700 \mathrm{~nm}$ after 2, 4, and $24 \mathrm{~h}$ in a UV-Visible Spectrometer (Perkin Elmer Lambda 950). Then, particle size analyzer (Model BT-90, Bettersize Instruments Ltd.) laser was used to analyze the particle size of silver nanoparticles.

JSM-6480 scanning electron microscope (SEM) was used to study the morphology of silver nanoparticles. In this analysis, a little amount of dried silver nanoparticles was taken on carbon coated copper grid, and images were taken [14]. The selected samples with least particle size were used for EDX analysis to do the elemental analysis.

2.3. Antifungal Bioassay with Silver Nanoparticles. Antifungal bioassay with silver nanoparticles synthesized using methanol plant extract was performed in vitro against $A$. terreus, following the protocol by Waheed et al. [15]. Briefly, malt extract medium was autoclaved and cooled at room temperature. Six concentrations, i.e., 1, 1.5, 2, 2.5, 3, and $3.5 \%$, were set up by addition of $1.5,3,4.5,6,7.5$, and $9 \mathrm{~mL}$ of stock solution of nanoparticles in flasks containing $58.5,57,55.5,54,52.5$, and $51 \mathrm{~mL}$ of malt extract media to make to volume up to $60 \mathrm{~mL}$. Also, $60 \mathrm{~mL}$ of media was used as control treatment. Chloromycetin was added in solution to control bacterial contamination. Three replicates were prepared from each dose by dividing into three flasks. Inoculation was performed using a freshly prepared culture of $A$. terreus, which were filtered after 7 days of inoculation with the help of preweighed and labelled filter papers. Fungal biomass obtained after filtration was oven dried till obtained a constant weight and was plotted against conc. of nanoparticles used. Percentage of biomass inhibition of test fungus was checked by using the following formula:

$$
\begin{aligned}
& \text { Growth inhibition }(\%) \\
& =\frac{\text { Growth in control }- \text { Growth in treatment } \times 100}{\text { Growth in control }} .
\end{aligned}
$$




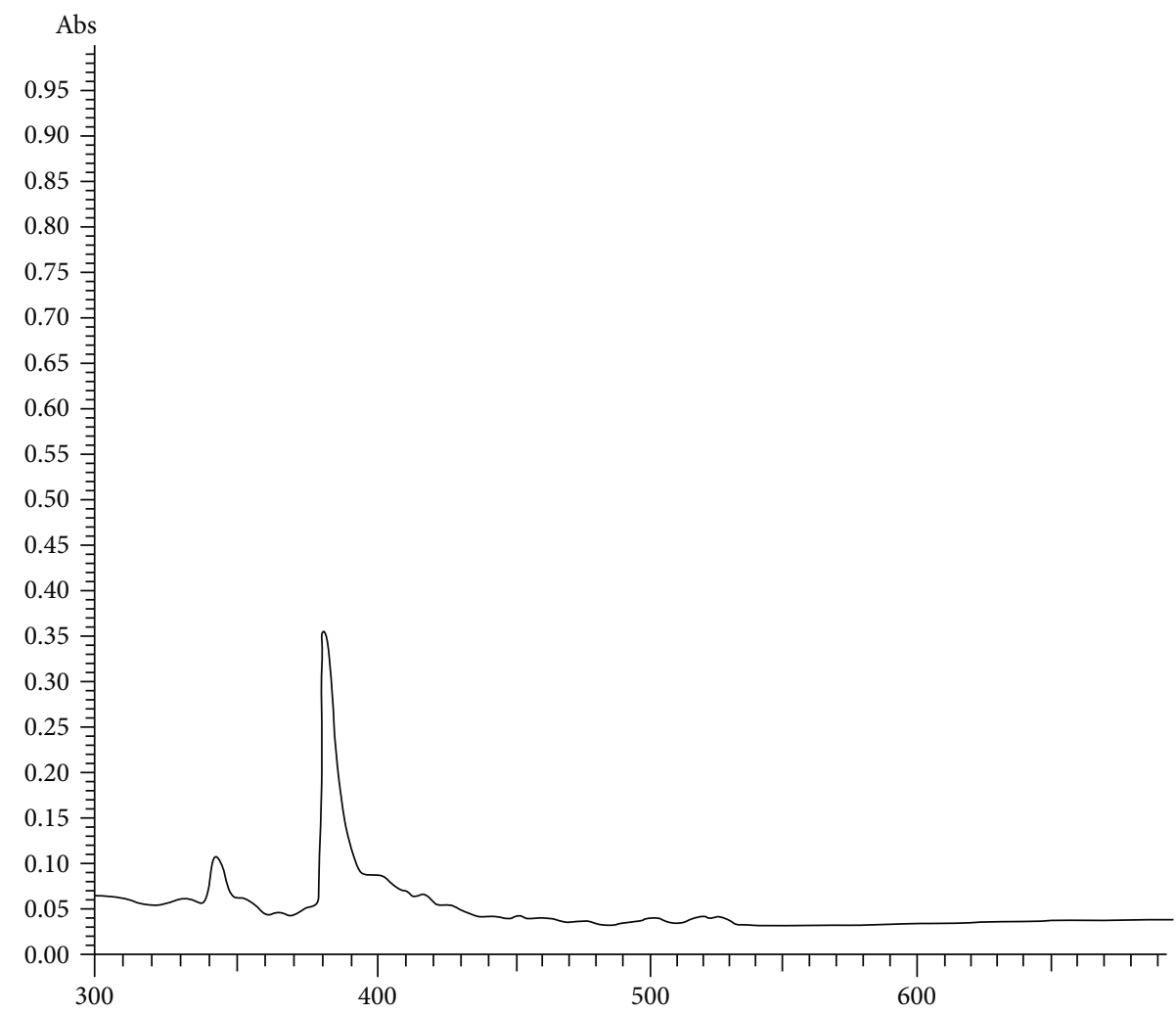

(a)

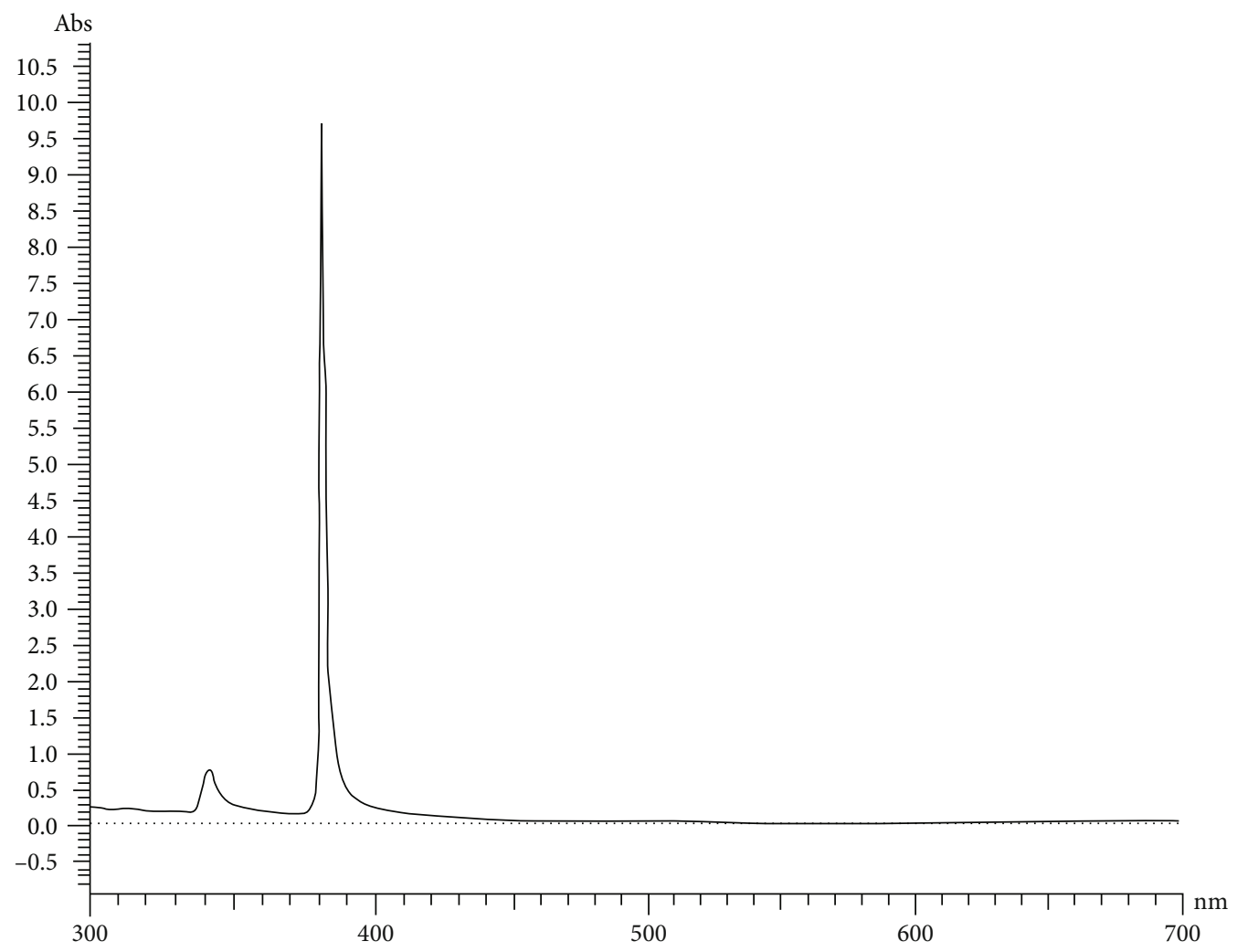

(b)

FIgURE 1: The UV/Vis spectrum of the silver nanoparticles synthesized from (a) methanol extract and (b) n-hexane fraction from extract of C. album. 


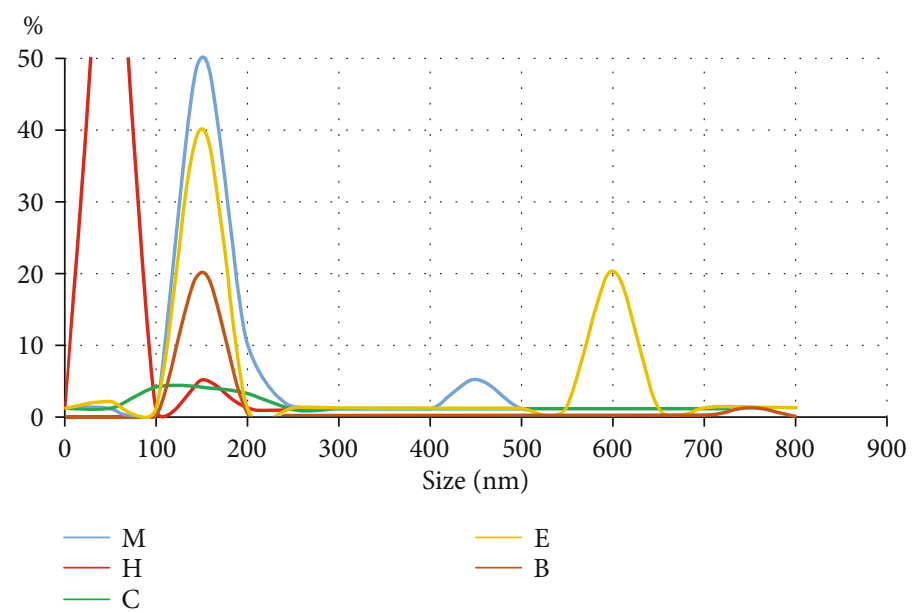

FIgURE 2: Particle size analysis of silver nanoparticles of C. album, where colored lines are indicating AgNPs of relative fractions. M: methanol; H: n-hexane; C: chloroform; E: ethyl acetate; B: n-butanol.

2.4. Antifungal Assay with Silver Nanoparticles of Isolated Fractions. Plant extract $(30 \mathrm{~g})$ was soaked in $100 \mathrm{~mL}$ methanol. Then, solution was evaporated leaving $2 \mathrm{~g}$ of gummy mass which was partitioned among $n$-hexane, chloroform, ethyl acetate, and $n$-butanol. Four isolated fractions were prepared from the abovementioned method and used for formation of silver nanoparticles by dissolving gummy mass in distilled water and then mixing with the $4 \mathrm{mM}$ silver nitrate solution separately. Each beaker of 4 fractions was covered using an aluminum foil and then kept in darkness for $2 \mathrm{~h}$ for incubation. Change in color was observed after intervals of 2, 4, and $24 \mathrm{~h}$. Then, solution was centrifuged at $5000 \mathrm{rpm}$ for $10 \mathrm{~min}$, and the supernatant was removed, and pellet was stored at $4^{\circ} \mathrm{C}$.

Nanoparticles from these fractions were evaluated against $A$. terreus over serial dilution method presented by Waheed et al. [15]. For this purpose, stock solution of nanoparticles $(20 \%)$ made from each fraction was divided into two concentrations $(0.1 \%$ and $0.2 \%)$. Their effect on growth of fungal colony was measured. A control treatment was also prepared without nanoparticles. Three replicates were prepared of each concentration. Mycelial disk from actively grown culture was inoculated in each petri plate.

2.5. Gas Chromatography-Mass Spectrometry Analysis (GC$M S)$. $n$-Hexane fraction of C. album extract was analyzed by using gas chromatography-mass spectrometry (GC-MS). The sample analysis was performed on GC-MS-QP 2010 chromatograph equipped with a DB-5 capillary column $(0.25 \mu \mathrm{m}, 0.25 \mathrm{~mm}, 30 \mathrm{~mm})$. The ionization voltage was of $70 \mathrm{eV}, \mathrm{m} / \mathrm{z}$ scan range $55-950 \mathrm{Da}$, and the oven temperature was kept at $45^{\circ} \mathrm{C}$ for $1 \mathrm{~min}$. After that, temperature was gradually increased at a rate $10^{\circ} \mathrm{C} \mathrm{min}^{-1}$, and up to $200^{\circ} \mathrm{C}$ was maintained for $5 \mathrm{~min}$ by using carrier gas (helium). The temperature of injector was kept $200^{\circ} \mathrm{C}$, and detector temperature was $250^{\circ} \mathrm{C}$. Qualitative analysis was done by comparing the retention times, indices, and mass spectra with the corresponding data in the literature (NIST Library word software).
2.6. Statistical Analysis. Data obtained were analyzed statistically by analysis of variance followed by DMRT (Duncan's multiple range test) with $5 \%$ level of significance as likelihood $p$ values, utilizing the PC programming Costat, cs6204 W.exe [16].

\section{Results and Discussion}

In this study, C. album leaf extract was used for nanoparticle synthesis. Plant extract was mixed with salt solution, and color changes indicated the nanoparticle synthesis, with characterization being done using UV-Visible spectroscopy, particle size analyzer, and SEM. Nanoparticles synthetized from $C$. album showed maximum absorption at wavelength ranging from 300 to $700 \mathrm{~nm}$ (mean, $380 \mathrm{~nm}$ ), with maximum absorption peaks corresponding to the confirmation of silver nanoparticle synthesis (Figure 1(a)). When methanol plant extract was portioned in organic solvents, i.e., $n$-hexane, chloroform, ethyl acetate, and $n$ butanol, and nanoparticles synthesized from these fractions also showed maximum absorption at a wavelength range from 300 to $700 \mathrm{~nm}$ (mean, 382) (Figure 1(b)). Furthermore, particle size of silver nanoparticles, formed from various fractions of methanol extract of C. album, ranged from 1 to $200 \mathrm{~nm}$ mainly, and a comparison showed that n-hexane fraction showed minimum size of AgNPs formed (Figure 2). Later on, SEM was used for a detailed analysis of silver nanoparticles of plant extract. Results showed that plant extract (methanol) formed AgNPs with smallest size of $197 \mathrm{~nm}$ (Figure 3(a)), while in n-hexane fraction, AgNPs synthesized had $150 \mathrm{~nm}$ (Figure 3(b)). Similarly, in chloroform fraction, the smallest size of $133 \mathrm{~nm}$ was observed (Figure 3(c)), whereas Figures 3(d) and 3(e) are showing the SEM images of AgNps being formed by the ethyl acetate and $n$-butane fraction of the C. album with a minimum size of 161 and $150 \mathrm{~nm}$, respectively. SEM images also show that overall shape of silver nanoparticles formed by various fractions of C. album is oval to hexagonal. Likewise, Dwivedi and Gopal [17] researched on gold and silver nanoparticle synthesis with C. album aqueous 


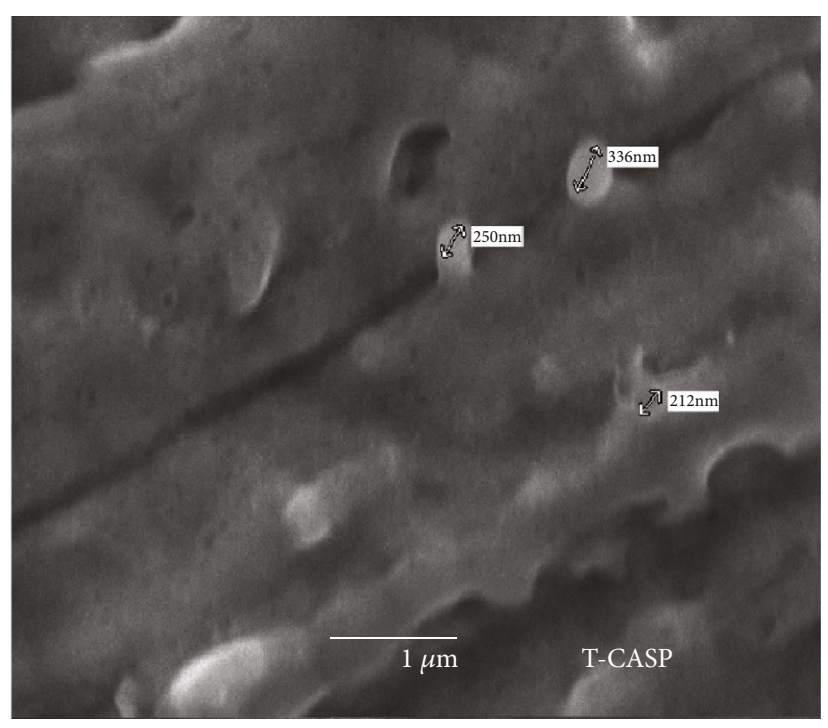

(a)

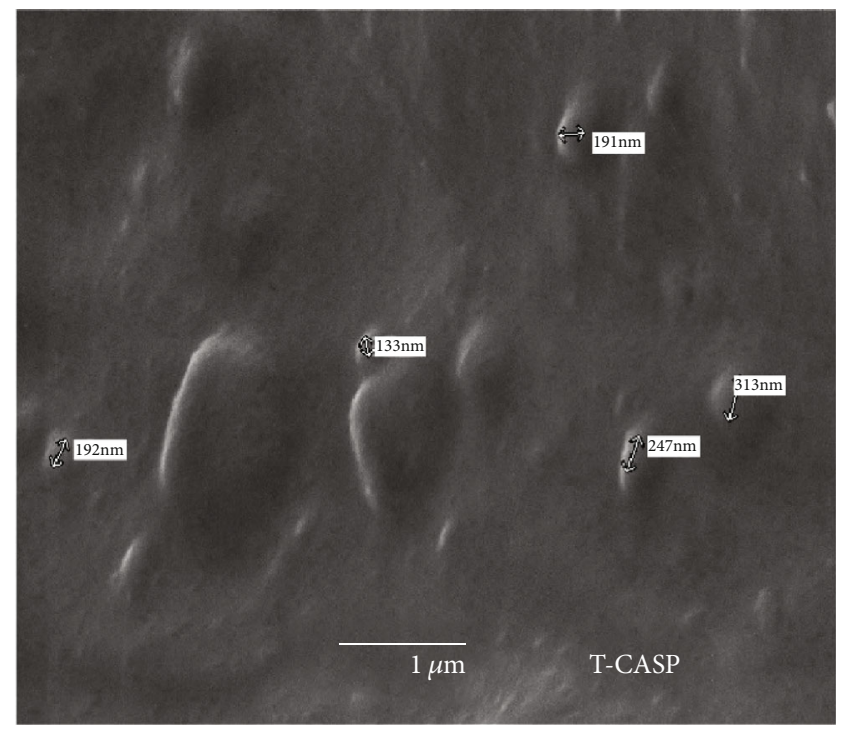

(c)

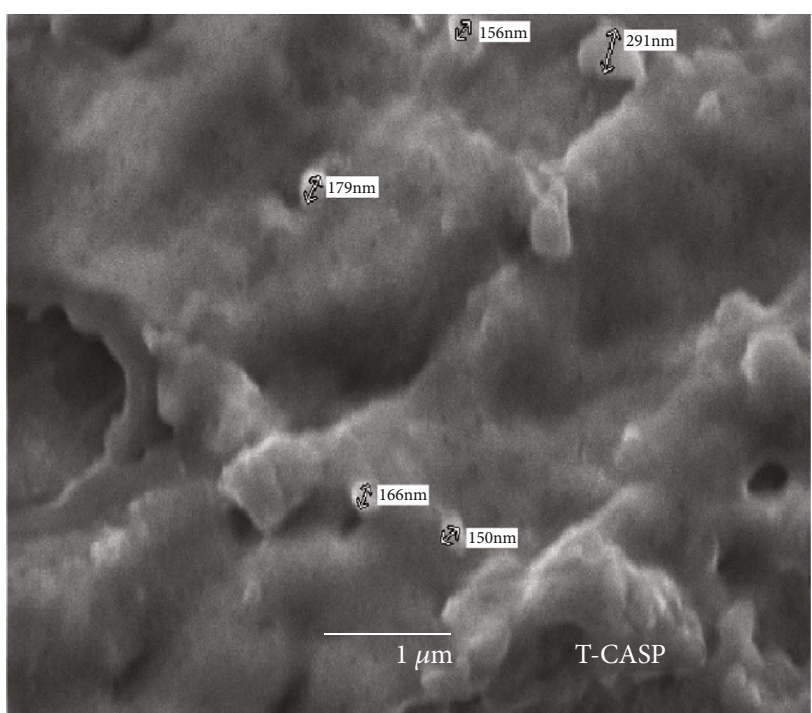

(b)

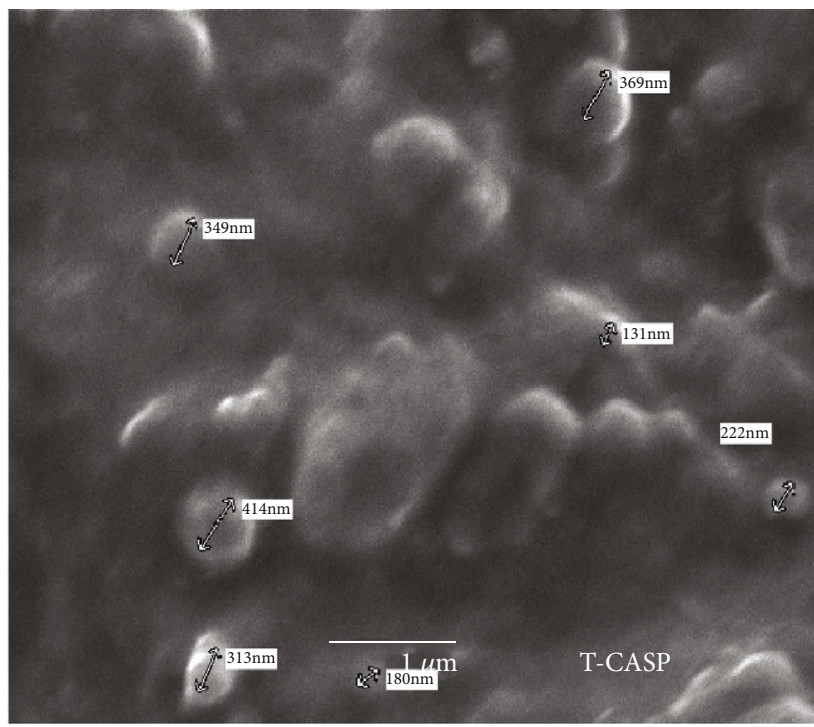

(d)

Figure 3: Continued. 


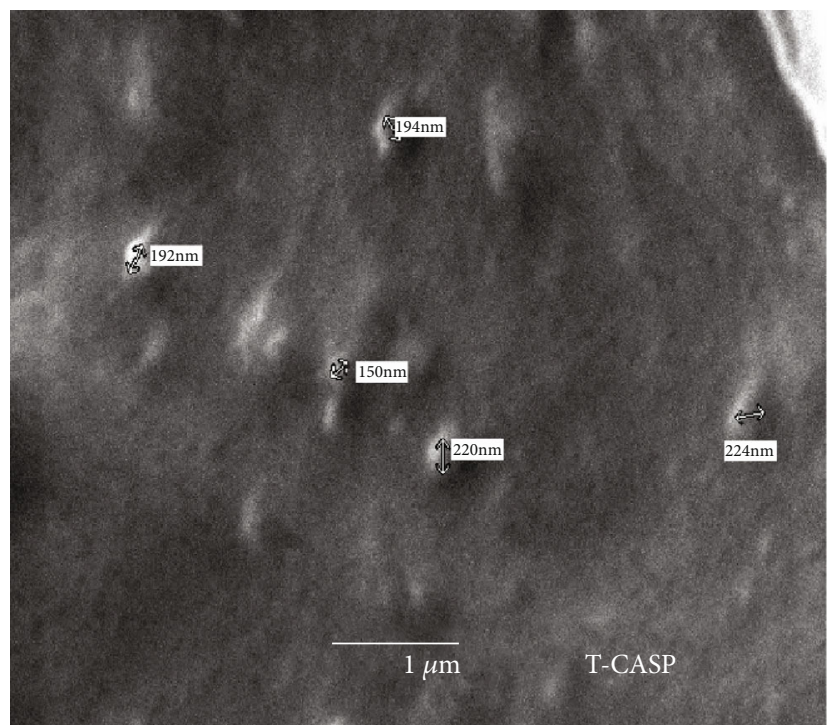

(e)

FIGURE 3: SEM analysis of silver nanoparticles of formed by: (a) methanol extract; (b) n-hexane fraction; (c) chloroform fraction; (d) ethyl acetate fraction; (e) n-butanol fraction of C. album.

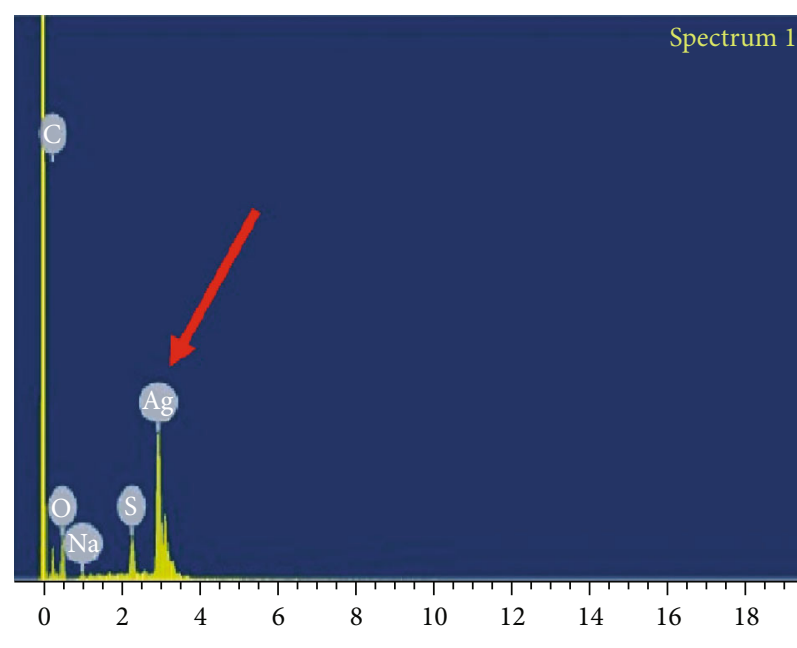

Full scale 3776 cts cursor: 0.000

(a)

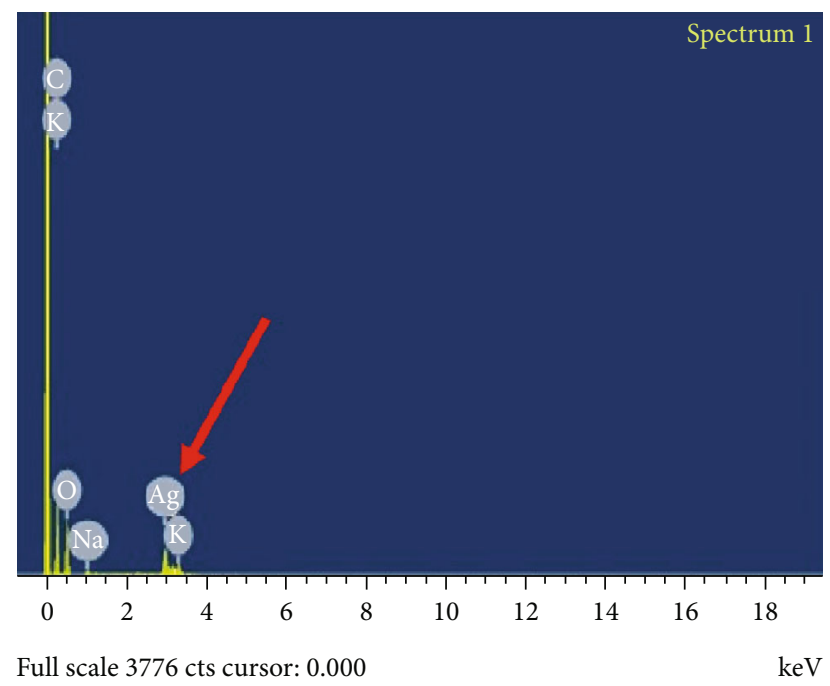

(b)

FIGURE 4: EDX analysis of silver nanoparticles synthesized from (a) methanol extract and (b) n-hexane fraction from extract of C. album.

extracts with $1 \mathrm{mM}$ salt solution and found an absorption peak at $460 \mathrm{~nm}$, and in SEM, a quasi-spherical shape was observed. Carrillo-Lopez et al. [18] reported similar results while using C. ambrosioides as a source plant. Physical and chemical techniques also exist for nanoparticle synthesis, but biological method is dominated over other methods as small amounts of plant material are used for reduction, and stabilization and chemicals involved are natural and environment friendly [19]. C. album has been reported to have a number of phytochemicals like phenols, alkaloids, saponins, carotenes, lignans, essential oils, etc., which have strong antioxidant and reducing capability $[12,20,21]$. These antioxidants act as capping and stabilizing agents for NPs formed. Various fractions of C. album were used in present study to find the potential of various metabolites to stabilize the nanoparticles. If metabolites present in plant extract are not able to stabilize properly, nanoparticles formed may give rise to their own aggregates, thus increasing their overall functional size and reducing their effectivity [18]. Present study proved the fact in terms of size of nanoparticles formed, as different sizes of NPS are formed by different fractions, and smallest size was obtained by n-hexane fraction of plant extract used. EDX analysis of plant AgNPs formed by plant extract (Figure 4(a)) and n-hexane fraction (Figure 4(b)) clearly shows the presence of silver, further confirming the synthesis of silver nanoparticles. 


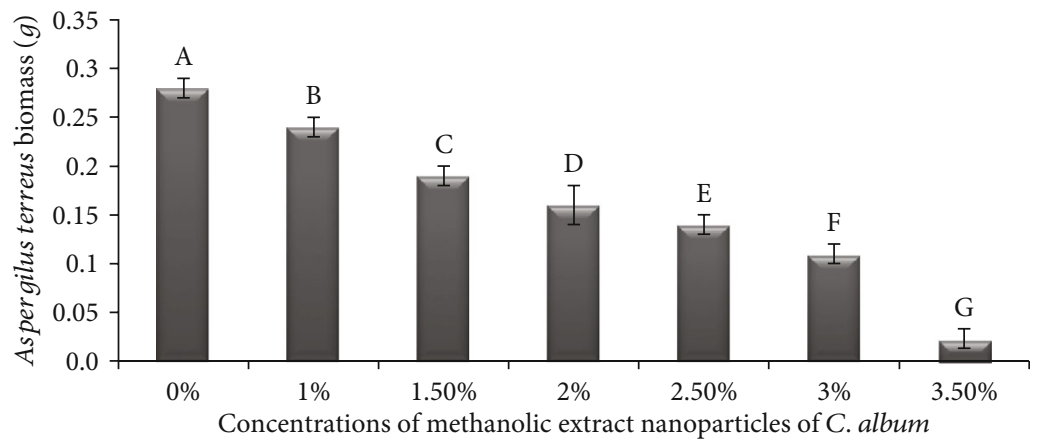

Figure 5: Decrease in A. terreus biomass after application of C. album silver nanoparticles.

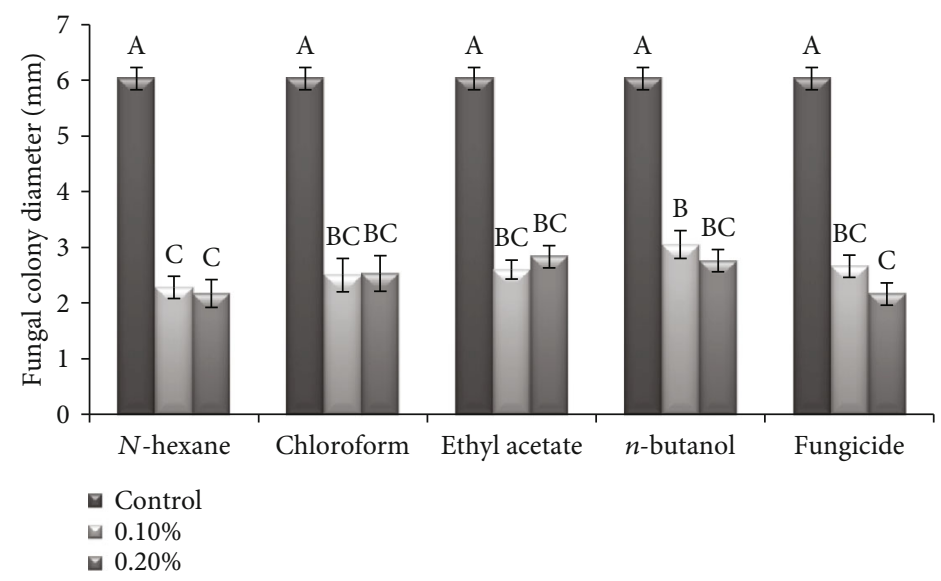

FIgURE 6: Antifungal activity of silver nanoparticles of different organic fractions of C. album.

All applied concentrations of C. album extract nanoparticles markedly retarded the test fungal biomass (Figure 5). Minimum biomass of fungus, i.e., $0.023 \mathrm{~g}$ ( $92 \%$ reduction), was observed at $3.5 \%$ concentration of silver nanoparticles of C. album methanol extract. The other concentrations, i.e., $1.5,2,2.5$, and $3 \%$, were capable of effectively inhibiting the test fungal growth by $32.1 \%, 40.4 \%, 50.0 \%$, and $60.7 \%$, respectively, when compared to control treatment. Finally, at $1 \%$, conc. of NPs, only $14 \%$ reduction in fungal growth was observed $(0.24 \mathrm{~g}$ fungal biomass as compared to $0.28 \mathrm{~g}$ fungal biomass in control). However, all applied concentrations of nanoparticles derived from C. album organic fractions significantly reduced the $A$. terreus growth (Figure 6), with the $n$-hexane fraction nanoparticles being stated as strongest fungicide as they were highly effective at both selected concentrations $(0.1 \%$ and $0.2 \%)$ leading up to 62 $64 \%$ inhibition in the fungal biomass. The chloroform fraction nanoparticles also retarded the A. terreus biomass up to $58 \%$, while $n$-butanol nanoparticle fraction was found comparatively less effective, with only $49 \%$ and $54 \%$ retardation. Finally, the ethyl acetate nanoparticles led to $56 \%$ and $53 \%$ retardation in the $A$. terreus diameter. These antifungal results may be correlated with the sizes of AgNPs formed; the smaller is the size of nanoparticles, more efficient they are to cross the fugal cell wall [22]. Small dimensions of acting nanoparticles help them to penetrate fungal hyphae by interacting with cell membranes and finally attacking fungal cell DNA and proteins. This usually leads fungal cells to death $[23,24]$.

GC-MS analysis was performed to the most effective fraction, and a total of 18 compounds were identified, namely, belonging to phenols, hydrocarbons, steric acids, propionic acid hydrazine, carbonyl compounds, and aromatic hydrocarbons. In detail, following chemical composition comprises of aromatic hydrocarbons, such as 1,3-cyclopentadiene-5-(1 methylethylidene and o-xylene), ethyl benzene, octadecane, nonane, decane, 2-methylheptane, n-hexadecane, 2-methylheptane, and eicosane, were identified, along with carbonyl compounds, such as 4,4-dimethyl-3-hexanone, and phenols, like stearic acid, propionic acid hydrazide, and 2,4-di-T-butylphenol (Table 1 and Figure 7). Data obtained here is corroborated by that obtained by Sherazi et al. [8], who identified carboxylic acids, fatty acids, and hydrocarbons in GC-MS analysis of C. album $n$-hexane fraction. Similarly, Yuan et al. [25] performed GC-MS analysis of C. album and showed that highest peak was observed between 5.24 and 6.24 min of retention time. The authors also found the presence of aromatic hydrocarbons, i.e., ethyl benzene, O-xylene, P-xylene, and 1ethyl-4-methylcyclohexane at higher amounts. These aromatic hydrocarbons possess antifungal potential, namely, 
TABLE 1: GC-MS analysis of n-hexane extract of C. album leaves.

\begin{tabular}{|c|c|c|c|c|c|}
\hline Sr. no & $\mathrm{RT}(\min )$ & Compound name & Molecular formula & MW & Peak area \% \\
\hline 1 & 5.242 & Ethyl benzene & $\mathrm{C}_{8} \mathrm{H}_{10}$ & 106.17 & 44.9 \\
\hline 2 & 5.242 & O-Xylene & $\mathrm{C}_{8} \mathrm{H}_{10}$ & 106.16 & 4.08 \\
\hline 3 & 5.558 & P-Xylene & $\mathrm{C}_{8} \mathrm{H}_{10}$ & 126 & 9.2 \\
\hline 4 & 6.242 & 1-Ethyl-4-methylcyclohexane & $\mathrm{C}_{9} \mathrm{H}_{18}$ & 126 & 14.28 \\
\hline 5 & 6.392 & Nonane & $\mathrm{C}_{9} \mathrm{H}_{20}$ & 128 & 3.06 \\
\hline 6 & 6.392 & Decane & $\mathrm{C}_{10} \mathrm{H}_{22}$ & 142.286 & 2.04 \\
\hline 7 & 8.233 & 2, 6-Dimethylendecane & $\mathrm{C}_{13} \mathrm{H}_{28}$ & 184.361 & 1.02 \\
\hline 8 & 8.233 & 2-Ethyl-4-methyl-1-pentanol & $\mathrm{C}_{8} \mathrm{H}_{18} \mathrm{O}$ & 130.22800 & 4.08 \\
\hline 9 & 8.233 & Octadecane & $\mathrm{C}_{19} \mathrm{H}_{40}$ & 268 & 1.02 \\
\hline 10 & 9.7 & 3,5,5-Trimethyl-1-hexene & $\mathrm{C}_{9} \mathrm{H}_{18}$ & 126 & 1.53 \\
\hline 11 & 9.7 & 2-Methylheptane & $\mathrm{C}_{8} \mathrm{H}_{18}$ & 114.23 & 0.51 \\
\hline 12 & 10.25 & 2-Bromooctane & $\mathrm{C}_{8} \mathrm{H}_{17} \mathrm{Br}$ & 193.12 & 0.51 \\
\hline 13 & 25.608 & 4,4-Dimethyl-3-hexanone & $\mathrm{C}_{8} \mathrm{H}_{16} \mathrm{O}$ & 128 & 1.02 \\
\hline 14 & 25.608 & Stearic acid hydrazide & $\mathrm{C}_{18} \mathrm{H}_{38} \mathrm{~N}_{2} \mathrm{O}$ & 298.52 & 3.06 \\
\hline 15 & 26.33 & Propionic acid hydrazide & $\mathrm{C}_{3} \mathrm{H}_{8} \mathrm{~N}_{2} \mathrm{O}$ & 104 & 3.06 \\
\hline 16 & 26.33 & 2,4-Di-t-butylphenol & $\mathrm{C}_{14} \mathrm{H}_{22} \mathrm{O}$ & 206 & 1.02 \\
\hline 17 & 50.475 & Eicosane, 2-methyl & $\mathrm{C}_{21} \mathrm{H}_{44}$ & 296 & 4.08 \\
\hline 18 & 51. & $n$-Hexadecane & $\mathrm{C}_{16} \mathrm{H}_{34}$ & 226.45 & 1.53 \\
\hline
\end{tabular}

Chromatogram (Zoom)

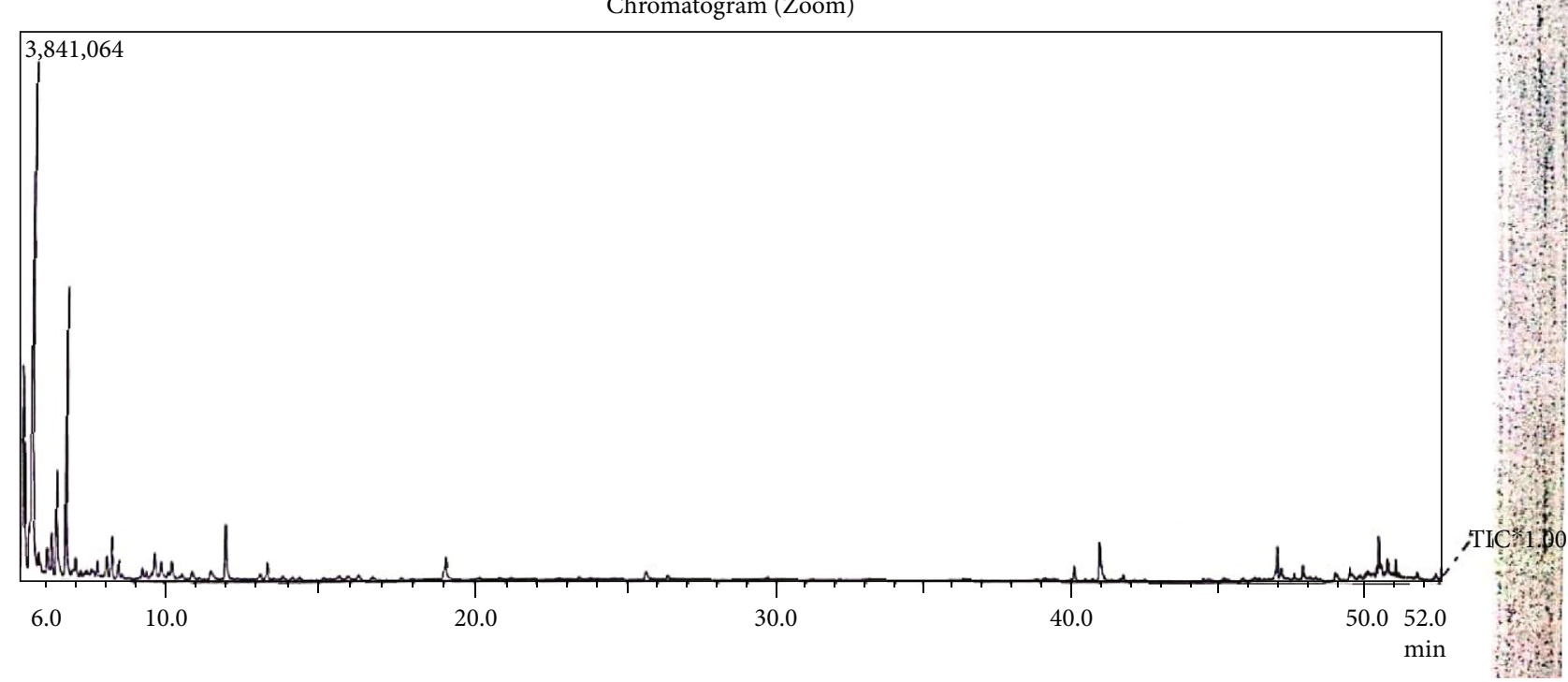

FIGURE 7: Chromatogram of $n$-hexane fraction of C. album.

ethyl benzene was able to boost a reduction in mycelial growth and spores' germination of F. oxysporum when compared to control. Earlier, Toliwal et al. [26] evaluated the antifungal activity of different fatty hydrazides against $A$. niger using immidil as standard. The authors stated inhibition ratios ranging from $50 \%$ to $70 \%$. In the current study, the steric acid hydrazide and propionic acid hydrazide were also identified and therefore may be the responsible for the good antifungal potential stated to the $n$-hexane fraction of C. album.

\section{Conclusion}

In short, this study concluded that $C$. album possesses high antifungal activity against $A$. terreus, silver nanoparticles of $C$. album revealing more effective against $A$. terreus; silver nanoparticles were prepared and tested from simple extract (maceration/microwave assisted) and from isolated organic fractions of plant, various organic fractions, viz., chloroform, $n$-butanol, and $n$-hexane. These silver nanoparticles were also assessed for antifungal activity, and $n$-hexane 
fraction led to $64 \%$ inhibition in $A$. terreus biomass. In addition, GC-MS revealed a high abundance of secondary metabolites, suggesting that they might be the main responsible for the $C$. album antifungal efficiency against $A$. terreus; 18 compounds were identified, namely, 1,3-cyclopentadiene-5-(1 methylethylidene and o-xylene), ethyl benzene, octadecane, nonane, decane, 2-methylheptane, $n$-hexadecane, 2-methylheptane, and eicosane, along with carbonyl compounds (4,4-dimethyl-3-hexanone) and phenols, like stearic acid, propionic acid hydrazide, and 2,4-di-T-butylphenol. These findings proved that $C$. album silver nanoparticles are highly effective against $A$. terreus.

\section{Data Availability}

The data used to support the findings of this study are available from the corresponding author upon request.

\section{Conflicts of Interest}

The authors declare no conflict of interests.

\section{Acknowledgments}

N.C.-M. acknowledges the Portuguese Foundation for Science and Technology under the Horizon 2020 Program (PTDC/PSI-GER/28076/2017).

\section{References}

[1] R. A. Samson, S. W. Peterson, J. C. Frisvad, and J. Varga, "New species in Aspergillus section Terrei," Studies in Mycology, vol. 69, no. 1, pp. 39-55, 2011.

[2] M. C. Fisher, D. A. Henk, C. J. Briggs et al., "Emerging fungal threats to animal, plant and ecosystem health," Nature, vol. 484, no. 7393, pp. 186-194, 2012.

[3] B. Louis, P. Roy, D. W. Sayanika, and N. C. Talukdar, “Aspergillus terreus Thom a new pathogen that causes foliar blight of potato," Plant Pathology \& Quarantine, vol. 3, no. 1, pp. 2933, 2013.

[4] B. A. Halo, R. A. Al-Yahyai, and A. M. Al-Sadi, "Aspergillus terreus inhibits growth and induces morphological abnormalities in Pythium aphanidermatum and suppresses Pythiuminduced damping-off of cucumber," Frontiers in Microbiology, vol. 9, p. 95, 2018.

[5] A. Rani, R. Singh, P. Kumar, and G. Shukla, "Pros and cons of fungicides: an overview," International journal of engineering sciences and research technology, vol. 6, pp. 112-117, 2018.

[6] M. A. Mohamed, H. A. HUSSEIN, and A. A. M. Ali, "Antifungal activity of different size controlled stable silver nanoparticles biosynthesized by the endophytic fungus Aspergillus terreus," Journal of Phytopathology and Pest Management, vol. 5, no. 2, pp. 88-107, 2018.

[7] K. Jabeen, A. Javaid, E. Ahmad, and M. Athar, "Antifungal compounds from Melia azedarach leaves for management of Ascochyta rabiei, the cause of chickpea blight," Natrual Product Research, vol. 25, no. 3, pp. 264-276, 2011.

[8] A. Z. Sherazi, K. Jabeen, S. Iqbal, and Z. Yousaf, "Management of Ascochyta rabiei by Chenopodium album extracts," Planta Daninha, vol. 34, no. 4, pp. 675-680, 2016.
[9] S. Rauf and A. Javaid, "Antifungal activity of different extracts of Chenopodium album against Fusarium oxysporum f. sp. cepae the cause of onion basal rot," International Journal of Agriculture and Biology, vol. 15, pp. 367-371, 2013.

[10] S. Hanif, K. Jabeen, and S. Iqbal, "Management of damping off disease by extracts of Albizia lebbeck (L.) Benth," Bangladesh Journal of Botany, vol. 46, no. 3, pp. 1019-1024, 2017.

[11] N. Khan, P. Zandi, S. Ali, A. Mehmood, M. Adnan Shahid, and J. Yang, "Impact of salicylic acid and PGPR on the drought tolerance and phytoremediation potential of Helianthus annus," Frontiers in Microbiology, vol. 9, p. 2507, 2018.

[12] S. Pandey and R. K. Gupta, "Screening of nutritional, phytochemical, antioxidant and antibacterial activity of Chenopodium album (Bathua)," Journal of Pharmacognosy and Phytochemistry, vol. 3, no. 3, pp. 1-9, 2014.

[13] S. Ahmed and S. Ikram, "Synthesis of gold nanoparticles using plant extract: an overview," Nano Research and Applications, vol. 1, no. 1, pp. 1-5, 2015.

[14] S. Das, U. K. Parida, and B. K. Bindhani, "Green biosynthesis of silver nanoparticles using Moringa Oleifera L. leaves," International Journal of Nanotechnology and Application, vol. 3, no. 2, pp. 51-62, 2013.

[15] N. Waheed, K. Jabeen, S. Iqbal, and A. Javaid, "Biopesticidal activity of Calotropis procera L. against Macrophomina phaseolina," African Journal of Traditional Complementary and Alternative Medicine, vol. 13, no. 6, pp. 163-167, 2016.

[16] R. G. D. Steel, J. H. Torrie, and D. A. Dickey, Principles and Procedures of Statistics: A Biometrical Approach, McGraw Hill Book Co., Inc, New York, USA, 1997.

[17] A. D. Dwivedi and K. Gopal, "Biosynthesis of silver and gold nanoparticles using Chenopodium album leaf extract," Colloids and Surfaces A: Physicochemical and Engineering Aspects, vol. 369, no. 1-3, pp. 27-33, 2010.

[18] L. M. Carrillo-López, R. M. Soto-Hernández, H. A. ZavaletaMancera, and A. R. Vilchis-Néstor, "Study of the performance of the organic extracts of Chenopodium ambrosioides for Ag nanoparticle synthesis," Journal of Nanomaterials, vol. 2016, Article ID 4714162, 13 pages, 2016.

[19] J. Pulit and M. Banach, "Plant extracts application in the process of nanosized silver preparation," Science technique, vol. 68, no. 1, pp. 47-52, 2014.

[20] F. Cutillo, M. DellaGreca, M. Gionti, L. Previtera, and A. Zarrelli, "Phenols and lignans from Chenopodium album," Phytochemical Analysis: An International Journal of Plant Chemical and Biochemical Techniques, vol. 17, no. 5, pp. 344-349, 2006.

[21] L. A. Usman, A. A. Hamid, N. O. Muhammad, N. O. Olawore, T. I. Edewor, and B. K. Saliu, "Chemical constituents and antiinflammatory activity of leaf essential oil of Nigerian grown Chenopodium album L," EXCLI Journal, vol. 9, pp. 181-186, 2010.

[22] M. Shammout and A. Awwad, "A novel route for the synthesis of copper oxide nanoparticles using Bougainvillea plant flowers extract and antifungal activity evaluation.," in A novel route for the synthesis of copper oxide nanoparticles using Bougainvillea plant flowers extract and antifungal activity evaluation, M. W. Shammout and A. M. Awwad, Eds., vol. 7, no. 1pp. 71-78, Chemistry International, 2021.

[23] D. H. Nguyen, J. S. Lee, K. D. Park et al., "Green silver nanoparticles formed by Phyllanthus urinaria, Pouzolzia zeylanica, and Scoparia dulcis leaf extracts and the antifungal activity," Nanomaterials, vol. 10, no. 3, p. 542, 2020. 
[24] S. M. Amini, "Preparation of antimicrobial metallic nanoparticles with bioactive compounds," Materials Science and Engineering: C, vol. 103, article 109809, 2019.

[25] J. Yuan, W. Raza, Q. Shen, and Q. Huang, “Antifungal activity of Bacillus amyloliquefaciens NJN-6 volatile compounds against Fusarium oxysporum f. sp. cubense," Applied and Environmental Microbiology, vol. 78, no. 16, pp. 5942-5944, 2012.

[26] S. Toliwal, K. Jadav, and K. Patel, "Synthesis and biological evaluation of fatty hydrazides of by-products of oil processing industry," Indian journal of pharmacy, vol. 71, no. 2, article 54282, pp. 144-148, 2009. 